\title{
Kurumsal İçerik Yönetimi Bileşenlerinin Bir Savunma Sanayii Organizasyonu Örneğinde Değerlendirilmesi*
}

\section{Evaluation of Enterprise Content Management Components within the Example of Defense Industry Organization}

\author{
Tolga ÇAKMAK** ve Özgür KÜLCÜ***
}

\begin{abstract}
Öz
Organizasyonlar doküman, belge, web içerik ve e-posta yönetimi gibi farklı amaçlarla geliştirdikleri bilgi sistemlerini kurumsal içerik yönetimi altında bütünleştirmeye yönelmektedirler. Çalışmamızda bu çerçevede Türkiye'de bir savunma sanayii kuruluşundaki koşulların ve beklentilerin kurumsal içerik yönetimi bileşenleri açısından analiz edilmesi amaçlanmıştır. Belirlenen bu amaç kapsamında geliştirilen web tabanlı bir anket uygulaması ile çalışanların günlük işlerinde kullanmış oldukları doküman yönetimi sistemleri, elektronik posta sistemleri, Web içerik yönetimi uygulamaları ve Evrak/Belge Sistemleri 167 birimden 337 kullanıcı ile analiz edilmiştir. Yapılan analizlere göre; kurumda elektronik posta yönetimi sistemlerinin diğer sistemlere göre daha iyi düzeyde olduğu, en çok kurumsal belge yönetimi sistemlerinin geliştirilmesi, kurumun bütününü kapsayan bir sistem yaklaşımının yapılandırılması ve bu yöndeki farkındalığın artırılması gerektiği vurgulanmıştır.
\end{abstract}

Anahtar sözcükler: Içerik yönetimi, Kurumsal içerik yönetimi, Kurumsal içerik yönetimi bileşenleri, Savunma sanayii, Türkiye

\begin{abstract}
Organizations tend to integrate the systems, such as document, records, web content and e-mail management that they develop for various purposes under enterprise content management. In this respect, the aim of this study is to analyze the current conditions and expectations of a defense industry organization in Turkey. According to this aim, the document management systems, electronic mail systems, Web content management applications used by the employees while running their day-to-day activities and the document/records systems used for official correspondence in 167 departments by 337 users within an organization specialized in defense industry in Turkey have been analyzed with a web based survey. Results show that the

\footnotetext{
Bu makale ve makalede kullanılan veriler, Tolga Çakmak'ın (Çakmak, 2011) Hacettepe Üniversitesinde hazırladığı yüksek lisans tezine dayandırılmıştır.

** Arş. Gör., Hacettepe Üniversitesi, Edebiyat Fakültesi, Bilgi ve Belge Yönetimi Bölümü, Beytepe - Ankara \{tcakmak@hacettepe.edu.tr\}

*** Doç. Dr., Hacettepe Üniversitesi, Edebiyat Fakültesi, Bilgi ve Belge Yönetimi Bölümü, Beytepe - Ankara \{kulcu@hacettepe.edu.tr\}
} 
electronic mail management systems in the related organization are at a higher level than the other systems, and records management systems should be developed more than other analyzed systems. Implementation of an enterprise content management system and increasing the awareness of employees about enterprise content management are also recommended by the authors.

Keywords: Content management, Enterprise content management, Enterprise content management components, Defense industry, Turkey

\section{Giriş}

Kurumların giderek artan rekabet ortamında mücadele edebilmeleri, iç ve dış müşterilerinin gereksinimlerini karşılayabilmeleri ve hizmetlerini geliştirebilmelerinde bilgi yönetimi uygulamalarının son derece önemli bir yeri vardır. Güçlü bir bilgi sistemine sahip kurumlar, kendi sektörlerinde kurumsal etkililiği sağlamakta diğerlerinden bir adım öne çıkabilmektedirler. Kurumsal verimlilikte birimler arasındaki bilgi akışının doğru zamanda hızlı ve etkin biçimde sağlanması önemlidir. Bu bağlamda kurumlar bilgi akışının sağlanmasında farklı işlevleri taşıyan birçok sistemden ve araçtan faydalanabilmektedirler. Bu sistemler, bir yandan kurumun idari yapısına ve kurum kültürüne göre işleyişi tanımlarken diğer yandan kurumsal kararlara kaynak teşkil etmektedir. Öte yandan teknolojik olanaklar ve yaşanan gelişmeler, kurumlarda farklı içerikte bilgi kaynaklarının hızla çoğalmasına yol açmakta; kaynaklara etkin erişimin sağlanmasına yönelik sistemlerin geliştirilmesini gerekli kılmaktadır. Kurumsal bilgi sistemlerine dönük yeni yaklaşımlar, üretilen farklı içerikteki bilgi kaynaklarına yönelik ayrı bilgi sistemleri geliştirmek yerine farklı içerik unsurlarının tek bir noktadan ve bütünleşik bir sistem üzerinden daha etkin yönetimine dönük modelerin geliştirilmesini gerekli kılmaktadır (Wilkoff, Walker, Root ve Dalton, 2001, s.2). Kurumlarda bütünleşik sistem yaklaşımını taşıyan kurumsal içerik yönetimi uygulamaları bu çerçevede değerlendirilmektedir.

Yapılan çalışmalarda kurumların içerik yönetimi uygulamaları geliştirebilmeleri için öncelikle kendi bilgi sistemlerine dönük ayrıntılı analizleri; süreçler (geliştirme ve dağıtım), teknoloji (donanım, yazılım ve standartlar) ve içerik (kullanıcılar, bilgi sistemleri) unsurlarını göz önüne alarak yapmaları gerektiği ağırlıklı olarak vurgulanmaktadır (Tyrväinen, Päivärinta, Salminen ve livari, 2006). Çalışmamız çerçevesinde de, içerik ve içerik yönetimi uygulamaları genel hatlarıyla ele alınmakta, günümüz kurumsal yapılarında ortaya çıkan kurumsal içerik yönetimi yaklaşımı ve kurumsal içerik yönetimi bileşenleri anlatılmaktadır. Söz konusu bileşenler ayrıca Türkiye'de faaliyetlerini sürdüren bir savunma sanayii organizasyonu örneğinde kullanıcılar açısından ele alınmaktadır.

\section{İçerik ve İçerik Yönetimi}

Başta teknoloji ile ilgili alanlar olmak üzere çeşitli araştırmalara konu olan içerik yönetimi, birçok araştırmaya kaynak teşkil etmiştir. İçerik yönetiminin kavramsal olarak 
açıklanmasında önce içerik kavramının ne olduğunun belirlenmesi gerekmektedir. Bu kavram tanım olarak genel bir ifadeyle; "bir şeyin içinde bulunanların bütünü, muhteva" olarak ifade edilmektedir (Türk Dil Kurumu, 2005, s.930). Oxford Sözlüğünde (2011) ise içerik; "bir web sitesi ya da elektronik ortamdaki bir aracın içerisinde mevcut olan kayıtlı bilgi" olarak nitelendirilmektedir. Kavramın aynı zamanda belge yönetimi alanı ile de ilişkilendirilerek "bir belgenin oluşturulma nedenlerinden biri" olarak ifade edildiği görülmektedir (National Archives and Records Service of South Africa, 2006, s.10). Yapılan çalışmalardan hareketle içeriğin; ilgili olunan alanla ya da konuyla ilgili ortaya çıkan bütün ürünleri ve/veya hizmetleri kapsayan, formattan bağımsız bir kavram olduğu anlaşılmaktadır. Günümüzde yaşanan hızlı bilgi artışının da etkisiyle hangi alanda olursa olsun içeriğin; yönetimsel uygulamaların kapsamında yer alan temel bir kavramı sembolize ettiği söylenebilir.

İçerik yönetimi kavramı ile olarak literatürde farklı yaklaşımlar bulunmaktadır. Daha çok kurumsal boyutlarda ele alınmış bir kavram karşımıza çıkan içerik yönetimi terim, web kaynakları ve elektronik ortamdaki bilgi kaynaklarına yönelik kullanılmaktadır. İçerik yönetiminin kapsam olarak ilgili olunan konuda bir bütünü içermesi ve bilginin bulunduğu ortamların çeşitlenmesinden kaynaklanan nedenlerden dolayı konu ile ilgili farklı yorumlar yer almaktadır. Bu çalışmalarda içerik yönetimi en genel anlamıyla; herhangi bir formdaki bilginin yayınlanmasını, organizasyonunu, yönetimini destekleyen işlemler ve teknolojiler bütünü olarak ele alınmıştır (Content Management, 2009). Web kaynakları açısından içerik yönetimi, web varlıklarının doğru zamanda, tutarlı, iş birliği sağlayan, tekrarlanabilir ve yeniden üretilebilir bir şekilde gelişimini yöneten bir disiplindir (Nakano, 2002, s.33). İçerik yönetiminin kurumsal açıdan ele alındığı yaklaşımlarda ise kavram; kurumsal bilginin oluşturulma, yayınlanma, paylaşılma ve depolanma süreçlerini içeren bir yapı olarak görülmektedir (Ozan, 2009, s.171; UCDAVIS, 2009a).

\section{Kurumsal İçerik Yönetimi}

Kurumlar, insanlar ve gruplar arası ilişki ağlarından oluşan ortak bir değerler dünyasını, zihinsel ve duygusal ilişkileri düzenleyen informal bir yapıyı geliştirip sürekliliğini sağlamaktadırlar (Vural, 2005, s.39). Günümüzde kurumların ürettikleri içerik unsurları kâğıt ortamından daha fazla elektronik ortamda bulunmaktadır. Kurumlar, sahip oldukları teknolojik olanaklar ve altyapıları ile sürekli olarak kurumsal bilgiye dayalı içerik oluşturmaktadırlar. Bu bağlamda kurum içi ya da kurumlar arası olaylar ve etkinliklerle ilgili sebep-sonuç ilişkilerini ve eğilimlerini inceleyerek bir kurumun başarılı ve etkinlikle idare edilmesi için geçerli ilkeleri ortaya koymaya çalışan yönetim bilimi; kurumların ürettiği içeriğe yönelik süreçleri de değerlendirmek durumunda kalmaktadır (Vural, 2005 , s.19). Kurumlar bu bağlamda yönetim süreçlerini sahip oldukları içerik unsurları üzerinde kullanmakta; işleyişlerinde etkililik ve verimlilik sağlamaya yönelik çalışmalar yürüterek çeşitli bilgi sistemlerinden faydalanmaktadırlar. Söz konusu sistemler, içerik yönetim sistemleri olarak adlandırılmaktadır. 
Kurumsal içerik yönetimi (KiY), akademik çalışmalarda ve uygulama alanında 2005 yılından itibaren yaygın olarak kullanılmaya başlanmış bir kavramdır (Tyrväinen ve diğerleri, 2006, s.627; Dilnutt, 2006, s.39). KiY'in içerik yönetimine yeni bir boyut kattığı ifade edilmektedir (Mescan, 2004, s.55). Özellikle uluslararası KiY derneği olan Association for Information and Image Management (AIIM) tarafından yapılan çalışmalar ilgili konudaki literatürün gelişmesine büyük ölçüde katkı sağlamıştır. 1943 yılında Ulusal Mikrofilm Derneği adıyla (National Microfilm Association) kurulan AlıM, ilerleyen dönemlerde günümüzdeki adını alarak dokümanları, içeriği, belgeleri ve iş süreçlerini yönetmede yenilikleri yakalamada ve gelişmeleri takip etmede kullanıcılara yardım etmeyi amaçlamıştır (AIIM, 2009). AlIM günümüzde bu amaçları sayesinde uluslararası KiY derneği olarak da anılmaktadır. AlıM tarafından yapılan son çalışmalarda KIYY, "kurumsal işlemlerle bağlantılı olan içerik ve dokümanların dağıtılması, korunması, depolanması ve oluşturulması için kullanılan strateji, yöntem ve araçlar bütünü" olarak ifade edilmektedir (AIIM, 2009; Kampffmeyer, 2006; Enterprise Content Management, 2009). Literatürde AlıM'nin dışında farklı tanımlamalar da yapılmıştır. Yapılan diğer çalışmalarda KIY; kurumlarda içeriğin üretimi, depolanması, yayınlanması ve kullanılması için oluşturulan üstverileri, içerik sunumlarına eklenen yazılım kodlarını, yapılandırılmamış, yarı yapılandırılmış ve yapılandırılmış bilgiyi bütünleştiren bir kavram olarak ifade edilmiştir (Tyrväinen ve diğerleri, 2006; Päivärinta ve Munkvold, 2005, s.1). Smith ve Mckeen (2003, s.647) KiY'i, dokümanlar, veriler, formlar, raporlar ve web sayfaları gibi içerik olarak kabul edilen bütün dijital varlıkların yaşam döngüsü boyunca yönetimi için gerekli beceriler, süreçler, araçlar ve stratejilerle ilgili bir alan olarak tanımlamıştır. KIY temel olarak, bir işletmedeki bilgi içeriğinin kullanıcılar ve diğer organizasyonlar arasındaki değişimini yetkilendirmelere dayalı iş akışını ifade etmektedir (Chieu, Zeng, ve Mohindra, 2008, s.1131).

\section{Kurumsal İçerik Yönetiminin Bileşenleri}

KIY uygulamalarında kullanılan bileşenler kurumsal bilgi sistemlerinde yer alan içerik unsurlarının bütünleşik bir yapıdan yönetimini ve kullanıcıların iş süreçlerinde etkililiğini sağlamaktadır. Bu süreçte KiY bileşenleri iş süreçlerinin hızlı ve kurumsal işleyişe uygun bir yapıda yürütülmesinde önemli bir etkiye sahiptir. KIY bileşenleri içerisinde en çok yönetim bileşeni ile bağlantılı bir yapı bulunduran kurumsal bilgi sistemleri, kurumlara göre farklılık göstermesine karşın belirli kategoriler altında toplanabilmektedir.

a. Web İçerik Yönetimi: KiY sistemi içerisinde kullanıcıların kurumsal işleyiş doğrultusunda bilgi ihtiyaçlarını karşılamayı hedefleyen web arayüzü ile ilgili işlemler web içerik yönetimi kapsamında ele alınmaktadır (Content-Managementjunction, 2011; McNay 2002, s.397). Kurum dokümanlarının ve kurumsal bilginin web üzerinde oluşturulması, yayınlanması ve yönetimi olarak tanımlanan web içerik yönetimi kurumsal amaçlar doğrultusunda çok yönlü olarak kullanılabilmektedir. Web içerik yönetimi kapsamında kurum yerel ağları ve portallar, internet üzerinden 
hizmet veren kurum web sayfaları yer almaktadır (Jenkins, Köhler ve Shacklaton, 2005, s.26). Web içerik yönetimi, KIY bileşenleri içerisinde çoğunlukla yönetim bileşeni ile birlikte dağıtım bileşeni kapsamında çalışmaların yürütüldüğü; kurum web sayfalarında standardizasyonu getiren bir KiY uygulamasıdır (McNay 2002, s.397; AlIM Europe ve AllM International, 2007).

b. Doküman Yönetimi: Günümüz kurumlarında yoğunlukla kullanılan içerik unsurlarından birisi de dokümanlardır. Kurumsal iş süreçlerine bakıldığında da çalışanlar tarafından eğitim notları, standartlar, teknik raporlar gibi sürekli bir doküman oluşturma eğilimi olduğu ve dokümanlar doğrultusunda iş süreçlerinin gerçekleştirildiği görülmektedir (Alsup, 2004). Dokümanların kullanımlarında kurumsal süreçlerde kanıt niteliği taşımalarının da etkisiyle genellikle doküman yönetim sistemlerinden faydalanılmaktadır. Kurumsal yapılarda KiY sistemleri içeriğinde doküman yönetimi uygulamaları yer almaktadır. Bu bağlamda işlev olarak doküman yönetimi sistemleri, dokümanların yaşam döngüleri süresince yetkilendirme, arama, navigasyon, sürüm kontrolü, üstveri hizmetleri, indeksleme gibi işlemleri gerçekleştirmektedir (Jenkins ve diğerleri, 2005, s.24; O'Callaghan ve Smits, 2005).

c. Belge Yönetimi: Doküman yönetiminde olduğu gibi belgeler de kurumsal iş süreçlerinde kanıt niteliği taşıyan, resmi işlemleri ve kurum içi/dışı yazışmaları sağlayan önemli unsurlardır. Kurumsal bilgi sistemlerinin getirdiği yaklaşımlar doğrultusunda belge yönetimi sistemleri ile belgelerin birimler ve/veya kurumlar arasındaki akışı sağlanmaktadır (Sprehe, 2005). KiY uygulamaları kapsamında da elektronik belgelerin yönetimi belgelerin yaşam döngüsü kapsamında gerçekleştirilmektedir. Bu bağlamda KiY, elektronik ortamda belgelerin üretilmesi, kurumsal işlemlerde kullanılması, depolanması, yeniden kullanımları için alıkonması ve yok edilmesi gibi işlemleri içermektedir (AIIM, 2011; Kampffmeyer, 2006; Jenkins ve diğerleri, 2005, s.24).

d. E-posta Yönetimi: E-postalar gelişen teknoloji ile birlikte kurumlar için en önemli bilgi iletişim unsurlarından biri olmuş ve kurumsal işleyişte resmi belge niteliği taşıyan unsurlar haline dönüşmüştür. Kurumsal iletişimin \%70'inden fazlasının e-postalar ile gerçekleştirilmesi, e-postaların en kritik bilgi yönetim sistemlerinden biri olarak nitelendirilmesini sağlamıştır (Stephens ve Wallace, 2003). KiY kapsamında kurumlar için giderek daha da önemli bir konuma gelen e-postaların yönetimi ile ilgili uygulamalar yer almaktadır. Bu uygulamalar, kurumsal politikalara göre e-postaların kurumsal süreçlerde arşivlenmesi, uzun süreli korunması, imhası gibi süreçleri içermektedir.

e. Dijital Varlık Yönetimi: Kurumsal işleyiş̧te üretilen web sayfaları, dokümanlar ve belgelerden farklı olarak video, fotoğraf gibi görsel ortamlar ve diğer ortamlar kurumun dijital varlıklarını oluşturur (Wilkoff ve diğerleri, 2001). Bu doğrultuda 
kurumlar giderek artan sayıdaki dijital unsurlar için yönetim ile ilgili sistemler kullanarak kurumsal işlemlerini gerçekleştirmektedirler. KIY uygulamaları video, resim gibi dijital varlıkların izlenmesi, dijitalleştirilmesi ve depolanması gibi işlemleri içermektedir (AIIM, 2011).

f. İş Akışı ve İş Süreçleri Yönetimi: İş surecleri calışanlarla icerik unsurları arasında bağlantılı olmasını sağlar. İş süreçleri yönetimi de çalışanların ortaklaşa çalışmalarında yapılandırılmış ve yapılandırılmamış ortamların oluşturulmasını ve böylelikle çalışanların içerikle etkileşimde bulunmalarını sağlayan bir yapıdır (Jenkins ve diğerleri, 2005, s.29). Bu kapsamda iş süreçleri yönetimi; kurumsal iş akışının fonksiyonelliğini geliştiren, işleyen ve veri takibini belirli bir metodolojiye dayanarak gerçekleştiren mekanizmalardır (AIIM, 2011).

Yukarıda sıralanan bileşenleri içeren KiY, günümüzde popüler bir araştırma alanını oluşturmaktadır. Literatürde uluslararası düzeyde içerik yönetimi uygulamaları çerçevesinde kurumsal bilgi sistemlerini ele alan pek çok çalışmanın yapıldığı dikkati çekmektedir (Gupta, Govindarajan ve Johnson, 2001; Reimer, 2002; Smith ve Mckeen, 2003; Asprey ve Middleton, 2003; Tyravainen, Salminen ve Paivarinta, 2003; Paivarinta ve Munkwold, 2005; Jenkins ve diğerleri, 2005; Shegda, Bell, Chin ve Gilbert, 2007; Broadbent, 2009).

\section{Yöntem}

Araştırmamızda incelenen savunma sanayii organizasyonunda kurumsal içerik sistemlerinin analizi kapsamında uygulanan anket aracılığıyla çalışanların günlük işlerde kullandıkları doküman yönetimi sistemlerine, e-posta sistemlerine, web içerik yönetimi uygulamalarına ve resmi yazışmalarda kullandıkları belge sistemlerine yönelik değerlendirme yapmaları istenmiştir. Değerlendirme sürecinde anketin her bir bölümü için doküman, belge gibi kavramlar tanımlanarak deneklerin kavramların neyi ifade ettiği açıklanmıştır. Hazırlanan ankette her bir uygulama ve sistem için Likert ölçeğine dayanan sekiz soru kullanılmıştır. Analizler sonucunda söz konusu sistemlerin tasarım, içerik, bilgi erişim, bilgi güvenliği, kurumsal iletişim, politikalar ve arşivleme ve uzun süreli koruma işlevlerine yönelik kullanıcı değerlendirmeleri ortaya çıkmıştır. Araştırmamız kapsamında uygulanan anket, kurumsal politikalar kapsamında bilgi sistemlerine erişim yetkisi olan çalışanlara kurum portalı ve e-posta yoluyla gönderilmiştir. 2 haftalık bir süre için açık bırakılan ankete kurum bünyesinde yer alan 167 birimden 337 kullanıcı cevap vermiştir. Araştırma kapsamında elde edilen bulgular PASW (Predictive Analytics SoftWare) programı kullanılarak analiz edilmiştir. Ayrıca katılımcı değerlendirmelerinden elde edilen aritmetik ortalama değerleri radar grafiklerden faydalanılarak yorumlanmıştır. 


\section{KiY Unsurlarının Değerlendirilmesine Yönelik Bulgular}

\section{Doküman Yönetimi Sistemlerine Yönelik Değerlendirmeler}

Analizler kapsamında ilk olarak doküman yönetimi sistemleri tasarım, içerik, bilgi erişim, kurumsal iletişim, politikalar ve içeriğin arşivlenmesi ve uzun süreli korunması açılarından ele alınmıştır (Tablo I).

Tablo I. Doküman Yönetimi Sistemlerinin Değerlendirilmesi ( $N=337)$

\begin{tabular}{lcccccccccccc}
\hline & \multicolumn{2}{c}{ Görüş Yok } & \multicolumn{2}{c}{ Zayıf } & \multicolumn{2}{c}{ Düşük } & \multicolumn{2}{c}{ Orta } & \multicolumn{2}{c}{ lyi } & \multicolumn{3}{c}{ Çok İyi } \\
\cline { 2 - 12 } & $\mathbf{N}$ & $\%$ & $\mathbf{N}$ & $\%$ & $\mathbf{N}$ & $\%$ & $\mathbf{N}$ & $\%$ & $\mathbf{N}$ & $\%$ & $\mathbf{N}$ & $\%$ \\
\hline Tasarım & 12 & 3,6 & 15 & 4,5 & 32 & 9,5 & 122 & 36,2 & 109 & 32,3 & 47 & 13,9 \\
İçerik & 9 & 2,7 & 8 & 2,4 & 18 & 5,3 & 100 & 29,7 & 141 & 41,8 & 61 & 18,1 \\
Erişim & 12 & 3,6 & 12 & 3,6 & 26 & 7,7 & 111 & 32,9 & 127 & 37,7 & 49 & 14,5 \\
Güvenlik & 22 & 6,5 & 4 & 1,2 & 10 & 3 & 65 & 19,3 & 124 & 36,8 & 112 & 33,2 \\
İletişim & 17 & 5 & 10 & 3 & 20 & 5,9 & 108 & 32 & 130 & 38,6 & 52 & 15,4 \\
Politikalar & 20 & 5,9 & 10 & 3 & 24 & 7,1 & 116 & 34,4 & 116 & 34,4 & 51 & 15,1 \\
Arşivleme & 15 & 4,5 & 7 & 2,1 & 14 & 4,2 & 87 & 25,8 & 124 & 36,8 & 90 & 26,7 \\
\hline
\end{tabular}

Tablo I'deki bulgular incelendiğinde, katılımcıların doküman yönetim sistemlerinin bilgi güvenliği özellikleri ile içeriğin arşivlenmesi ve uzun süreli korunması özelliklerini çoğunlukla iyi ve çok iyi şeklinde değerlendirdikleri görülmektedir (sırasıyla \%70 ve $\% 63,5)$. İyi ve çok iyi şeklinde yapılan değerlendirmelerde bu özellikleri içerik zenginliği $(\% 59,9)$, kurumsal iletişim $(\% 54)$, bilgi erişim $(\% 52,2)$, politikalar $(\% 49,5)$ ve tasarım $(\% 46,2)$ izlemiştir. Öte yandan katılımcılar doküman yönetim sistemini tasarım (\%14), bilgi erişim $(\% 11,3)$ ve bilgi politikaları $(\% 10,1)$ açılarından daha yetersiz bulmuşlardır. Doküman yönetimi sisteminin etkinlik alanlarını tespit etmeye yönelik aritmetik ortalama değerleri Şekil 1'de gösterilmektedir. 


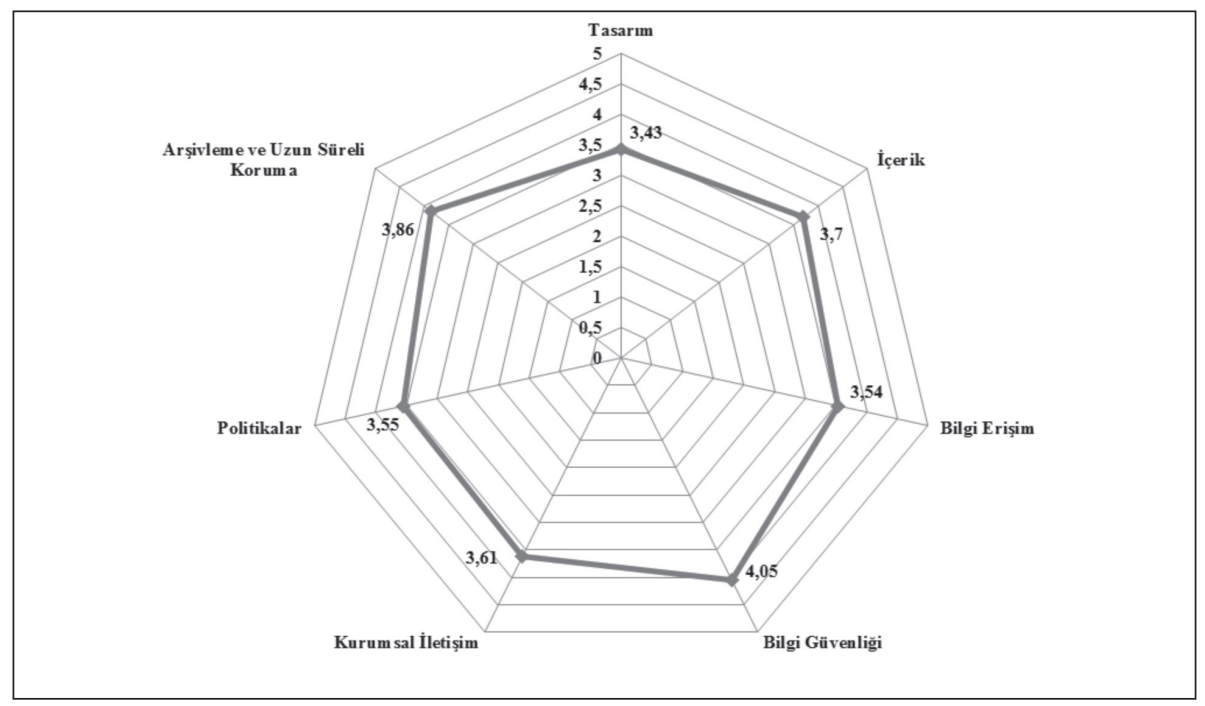

Şekil 1. Döküman Yönetim Sistemlerine Yönelik Değerlendirmeler

Aritmetik ortalamalar değerlendirildiğinde doküman yönetim sisteminin en güçlü olduğu alan bilgi güvenliğidir ( $\bar{x}=4,05 ; \sigma=0,896)$. Doküman yönetimi sisteminin tasarım ve bilgi erişim özellikleri ise diğer unsurlara göre daha düşük oranda etkindir. (sırasılya $\bar{x}=3,43 ; \sigma=1,006$ ve $\bar{x}=3,54 ; \sigma=0,967$ ).

\section{Web İçerik Yönetimi Sistemlerine Yönelik Değerlendirmeler}

Gerçekleştirilen analizler kapsamında Tablo II'de, kurumdaki web içerik yönetimi sistemleri tasarım, içerik, bilgi erişim, kurumsal iletişim, politikalar ve içeriğin arşivlenmesi ve uzun süreli korunması açılarından değerlendirilmektedir. 
Tablo II. Web İçerik Yönetimi Sistemlerinin Değerlendirilmesi (N=337)

\begin{tabular}{lccccccccccccc}
\hline & \multicolumn{1}{c}{ Görüş Yok } & \multicolumn{2}{c}{ Zayıf } & \multicolumn{2}{c}{ Düşük } & \multicolumn{2}{c}{ Orta } & \multicolumn{2}{c}{ İyi } & \multicolumn{2}{c}{ Çok İyi } \\
\cline { 2 - 14 } & $\mathbf{N}$ & $\%$ & $\mathbf{N}$ & $\%$ & $\mathbf{N}$ & $\%$ & $\mathbf{N}$ & $\%$ & $\mathbf{N}$ & $\%$ & $\mathbf{N}$ & $\%$ \\
\hline Tasarım & 1 & 0,3 & 15 & 4,5 & 49 & 14,5 & 91 & 27 & 124 & 36,8 & 57 & 16,9 \\
İçerik & 1 & 0,3 & 2 & 0,6 & 28 & 8,3 & 88 & 26,1 & 145 & 43 & 73 & 21,7 \\
Erişim & 1 & 0,3 & 15 & 4,5 & 24 & 7,1 & 99 & 29,4 & 137 & 40,7 & 61 & 18,1 \\
Güvenlik & 17 & 5 & 1 & 0,3 & 8 & 2,4 & 65 & 19,3 & 140 & 41,5 & 106 & 31,5 \\
İletişim & 4 & 1,2 & 6 & 1,8 & 20 & 5,9 & 101 & 30 & 142 & 42,1 & 64 & 19 \\
Politikalar & 9 & 2,7 & 7 & 2,1 & 19 & 5,6 & 107 & 31,8 & 146 & 43,3 & 49 & 14,5 \\
Arşivleme & 15 & 4,5 & 5 & 1,5 & 29 & 8,6 & 96 & 28,5 & 131 & 38,9 & 61 & 18,1 \\
\hline
\end{tabular}

Tablo II'de sunulan bulgulara göre, katılımcılar web içerik yönetimi sistemlerinin bilgi güvenliği ve içerik zenginliği unsurlarını diğerlerine göre daha iyi görmektedirler (iyi ve çok iyi seçeneklerinin toplamı sırasıyla $\% 73$ ve $\% 64,7$ ). Politikalar, kurumsal iletişim ve bilgi erişim özelliklerini orta seviyede görenlerin oranı sırasıyla \%31,8, \%30 ve $\% 29,4^{\prime}$ 'dür. Ayrıca web içerik yönetimi sistemlerinin tasarım, bilgi erişim ve içeriğin arşivlenmesi ve uzun süreli korunması özelliklerini yetersiz bulanların oranı sırasıyla $\% 19, \% 11,6$ ve \%10,1'dur. Web içerik yönetimi sistemlerinin etkinlik alanlarına ilişkin aritmetik ortalamalara ait bulgular Şekil 2'de sunulmaktadır.

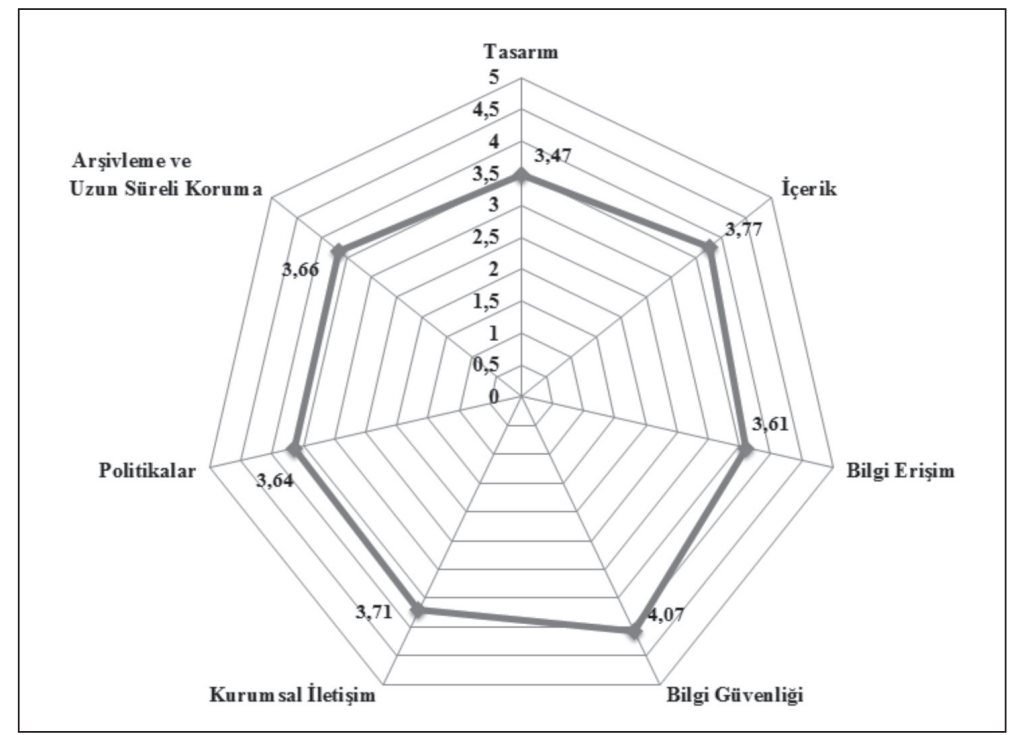

Şekil 2. Web Iç̧erik Yönetimi Sistemlerine Yönelik Değerlendirmeler 
Şekil 2'de web içerik unsurlarına ilişskin aritmetik ortalama değerleri incelendiğinde bilgi güvenliğine ilişkin kurumsal sistemin diğerlerine göre daha güçlü olduğu ortaya çıkmaktadır ( $\bar{x}=4,07 ; \sigma=0,812)$. İçerik zenginliği ve kurumsal iletişimi sağlama ise bilgi güvenliğini takip etmektedir (sırasıyla $\bar{x}=3,77 ; \sigma=0,903$ ve $\bar{x}=3,71 ; \sigma=0,905$ ). Kurumsal web içerik sisteminin tasarım özellikleri diğerlerine göre daha düşük seviyede yeterli bulunmuştur ( $\bar{x}=3,47 ; \sigma=1,073)$.

\section{Belge Yönetimi Sistemlerinin Değerlendirilmesi}

Kurumsal içerik yönetimi uygulamalarına yönelik analizlerde doküman yönetimi ve web içerik yönetimi ile ilgili değerlendirmelerin ardından kurumsal belge yönetimi uygulamaları tasarım, içerik, bilgi erişim, kurumsal iletişim, politikalar, içeriğin arşivlenmesi ve uzun süreli korunması açılarından analiz edilmiştir (Tablo III).

Tablo III. Belge Yönetimi Sistemlerinin Değerlendirilmesi (N=337)

\begin{tabular}{lcccccccccccc}
\hline & \multicolumn{2}{c}{ Görüş Yok } & \multicolumn{2}{c}{ Zayıf } & \multicolumn{2}{c}{ Düşük } & \multicolumn{2}{c}{ Orta } & \multicolumn{2}{c}{ İyi } & \multicolumn{3}{c}{ Çok Iyi } \\
\cline { 2 - 13 } & $\mathbf{N}$ & $\%$ & $\mathbf{N}$ & $\%$ & $\mathbf{N}$ & $\%$ & $\mathbf{N}$ & $\%$ & $\mathbf{N}$ & $\%$ & $\mathbf{N}$ & $\%$ \\
\hline Tasarım & 44 & 13,1 & 6 & 1,8 & 35 & 14,5 & 118 & 35 & 106 & 31,5 & 28 & 8,3 \\
İçerik & 44 & 13,1 & 4 & 1,2 & 30 & 8,9 & 115 & 34,1 & 111 & 32,9 & 33 & 9,8 \\
Erişim & 40 & 11,9 & 11 & 3,3 & 29 & 8,6 & 113 & 33,5 & 106 & 31,5 & 38 & 11,3 \\
Güvenlik & 44 & 13,1 & 12 & 3,6 & 27 & 8 & 93 & 27,6 & 107 & 31,8 & 54 & 16 \\
İletişim & 40 & 11,9 & 7 & 2,1 & 27 & 8 & 115 & 34,1 & 111 & 32,9 & 37 & 11 \\
Politikalar & 43 & 12,8 & 9 & 2,7 & 28 & 8,3 & 108 & 32 & 112 & 33,2 & 37 & 11 \\
Arşivleme & 41 & 12,2 & 7 & 2,1 & 27 & 8 & 103 & 30,6 & 109 & 32,3 & 50 & 14,8 \\
\hline
\end{tabular}

Tablo III'deki bulgulara göre belge/evrak yönetimi sistemleri bilgi güvenliği ve içeriğin arşivlenmesi ve uzun süreli korunması özellikleri açılarından diğerlerine göre daha yeterli bulunmuştur (iyi ve çok iyi seçeneklerinin toplamı sırasıyla $\% 47,8$ ve $\% 46,8$ ). Belge yönetim sistemlerinin tasarım, içerik zenginliği, kurumsal iletişimi sağlama ve bilgi erişim özelliklerini orta seviyede görenlerin oranı sırasıyla $\% 35, \% 34,1, \% 34,1, \% 33,5$ 'dir. Tasarım ve bilgi erişim özellikleri ise diğer özelliklere göre daha yetersizdir (sırasıyla $\% 16,3$ ve \%11,9).Katılımcıların belge/evrak sistemlerinin etkinlik alanlarını belirlemeye yönelik değerlendirmelerinin aritmetik ortalama değerleri Şekil 3'de verilmektedir. 


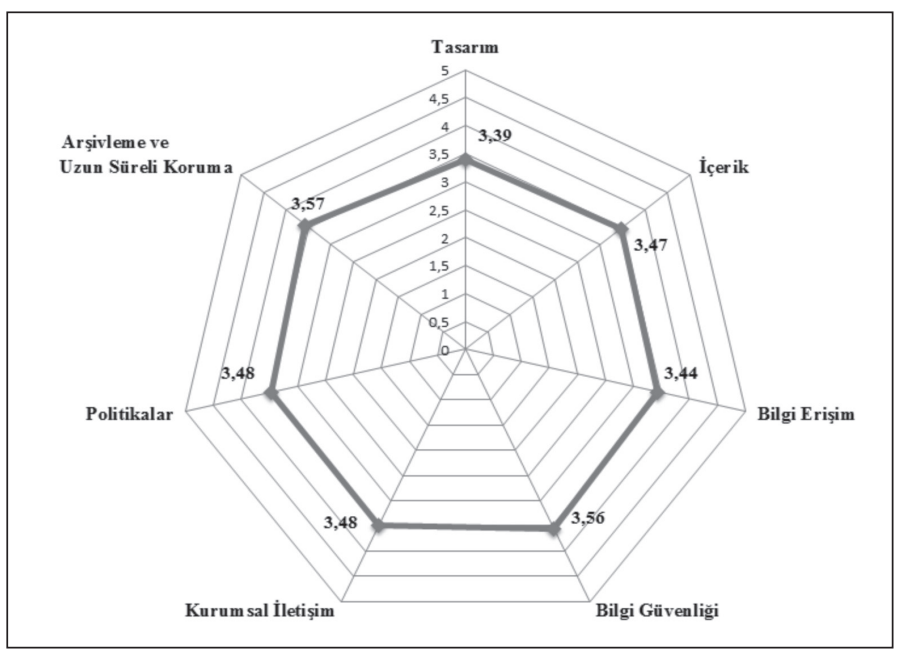

Şekil 3. Belge Yönetimi Sistemlerinin Değerlendirilmesi

Kurumsal işlemlerde belge sistemleri değerlendirildiğinde, tasarım özellikleri diğer özelliklere göre güçsüz çıkmaktadır ( $\bar{x}=3,39 ; \sigma=0,891$ ). Bilgi güvenliği ile arşivleme ve uzun süreli koruma özelliklerine ilişkin aritmetik ortalama değerleri orta ile iyi düzey arasındadır. Bu alanda yer alan aritmetik ortalama değerleri genel olarak incelendiğinde belge sistemleri, analiz edilen diğer tüm bilgi sistemlerine göre daha zayıftır.

\section{E-Posta Sistemlerine Yönelik Değerlendirmeler}

E-posta sistemlerinin tasarım, içerik, bilgi erişim, kurumsal iletişim, politikalar, içeriğin arşivlenmesi ve uzun süreli korunması ile ilgili bulgular Tablo IV'te verilmektedir.

Tablo IV. E-Posta Yönetimi Sistemlerinin Değerlendirilmesi (N=337)

\begin{tabular}{lrrrrrrrrrrrrr}
\hline & \multicolumn{2}{c}{ Görüş Yok } & \multicolumn{2}{c}{ Zayıf } & \multicolumn{3}{c}{ Düşük } & \multicolumn{2}{c}{ Orta } & \multicolumn{2}{c}{ İyi } & \multicolumn{2}{c}{ Çok İyi } \\
\cline { 2 - 13 } & N & $\%$ & N & $\%$ & N & $\%$ & N & $\%$ & N & $\%$ & N & $\%$ \\
\hline Tasarım & 11 & 3,3 & 6 & 1,8 & 13 & 3,9 & 75 & 22,3 & 137 & 40,7 & 95 & 28,2 \\
İçerik & 19 & 5,6 & 6 & 1,8 & 18 & 5,3 & 74 & 22 & 128 & 38 & 92 & 27,3 \\
Erişim & 8 & 2,4 & 10 & 3,0 & 29 & 8,6 & 77 & 22,8 & 128 & 38 & 85 & 25,2 \\
Güvenlik & 8 & 2,4 & 2 & 0,6 & 8 & 2,4 & 60 & 17,8 & 140 & 41,5 & 119 & 35,3 \\
İletişim & 6 & 1,8 & 5 & 1,5 & 9 & 2,7 & 63 & 18,7 & 135 & 40,1 & 119 & 35,3 \\
Politikalar & 15 & 4,5 & 10 & 3 & 21 & 6,2 & 70 & 20,8 & 137 & 40,7 & 84 & 24,9 \\
Arşivleme & 5 & 1,5 & 16 & 4,7 & 37 & 11 & 66 & 19,6 & 122 & 36,2 & 91 & 27 \\
\hline
\end{tabular}


E-posta sistemleri ile yukarıdaki sıralanan unsurlar, bütünüyle ele alındığında iyi ve çok iyi şeklindeki değerlendirmelerin \%60'ın üzerinde olduğu görülmektedir. Ayrıca bulgularda e-posta sistemlerinin bilgi güvenliği ve kurumsal iletişim özelliklerine yönelik değerlendirmelerde iyi ve çok iyi görülme oranları sırasıyla \%76,3 ve \%75,3'e çıkmaktadır. E-posta sistemlerinin arşivleme ve uzun süreli koruma ile bilgi erişim özellikleri ise katılımcılarca daha yetersiz $(\% 15,7$ ve \%11,6) bulunmuştur.

Katılımcıların e-posta sistemlerinin aritmetik ortalamalara yönelik etkinlik alanları ile ilgili analizler Şekil 4'te sunulmaktadır.

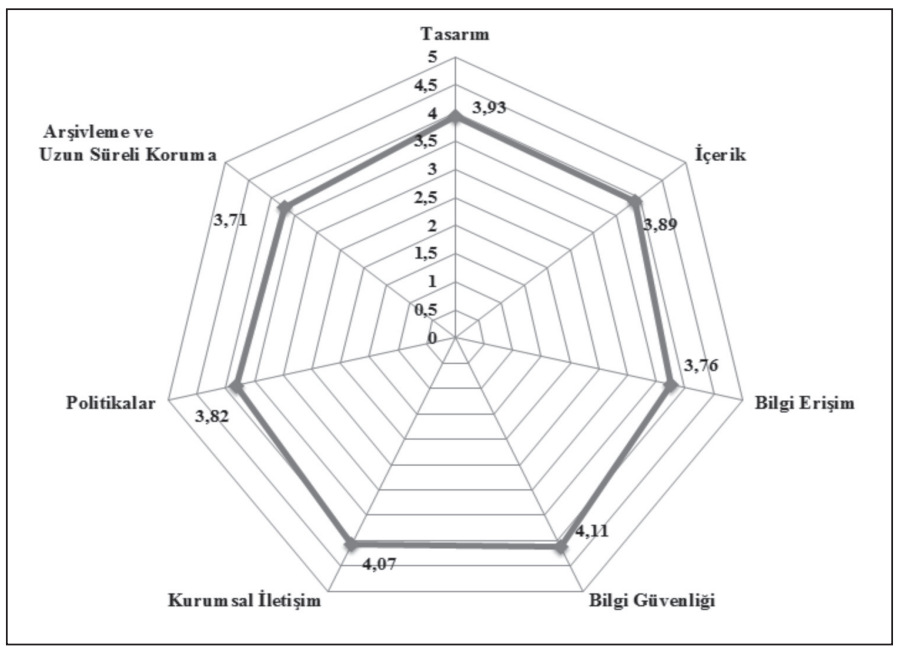

Şekil 4. E-posta Sistemlerine Yönelik Değerlendirmeler

E-posta sistemlerine yönelik analizlerde en yüksek aritmetik ortalama değerleri bilgi güvenliği ve kurumsal iletişim unsurlarındadır. Bulgular ayrıca Tablo IV'teki verileri destekleyecek şekilde katılımcıların e-posta sistemlerinin arşivleme, uzun süreli koruma ve bilgi erişim özelliklerini daha yetersiz bulduklarını göstermektedir.

\section{Doküman, Web İçerik, Belge ve E-posta Yönetim Sistemlerinin Genel Değerlendirmesi}

Araştırmamızda analiz edilen sistemlerin 7 unsura göre aritmetik ortalama değerlerinin karşılaştırılması Şekil 5'de verilmektedir. 


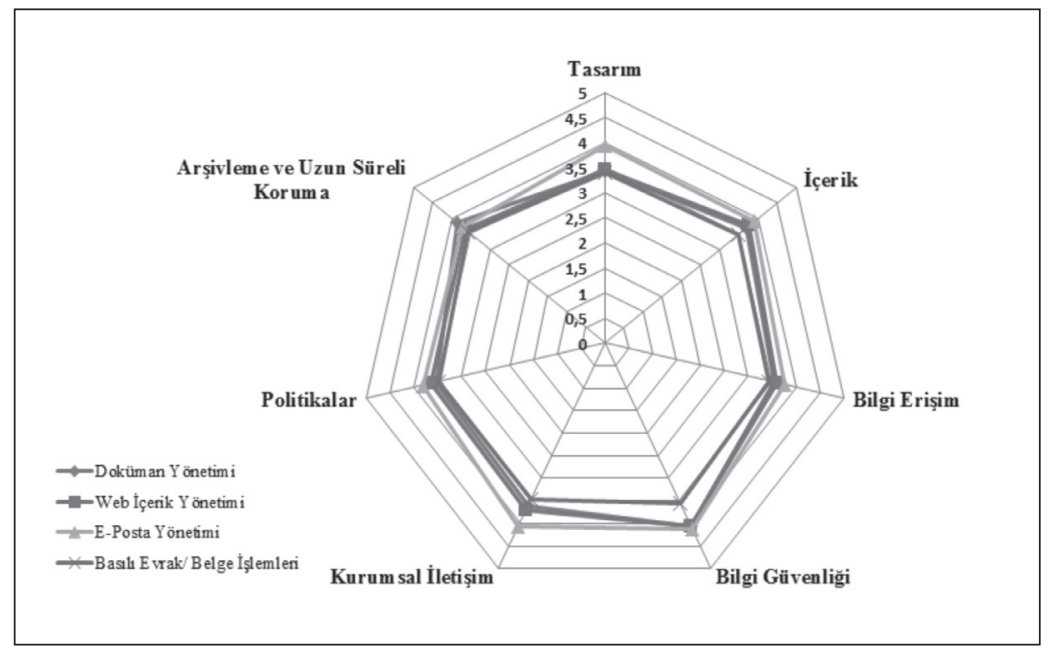

Şekil 5. Sistemlerin 7 Unsur Açısından Değerlendirilmesi

Şekil 5 değerlendirildiğinde e-posta sisteminin, içerik öğelerinin arşivlenmesi ve bu içeriğin uzun süreli korunması dışındaki 6 unsur da diğer sistemlere göre daha yüksek aritmetik ortalama değerine sahip olduğu görülmektedir. İçeriğin arşivlenmesi ve uzun süreli korunması ile ilgili değerlendirmelerde ise doküman yönetim sistemi daha başarılı görülmektedir.

Web içerik yönetimi sistemleri; tasarım, içerik zenginliği, bilgi erişim, kurumsal iletişim ve politikalara yönelik değerlendirmelerde e-posta sistemlerinin ardından ikinci sırada başarılı bulunmuştur. Doküman yönetim sistemleri bilgi güvenliği ile ilgili koşullarda e-posta sistemlerinden sonra ikinci sırada etkin görülmektedir.

Değerlendirmeler genel olarak web içerik yönetimi ile doküman yönetimi sistemlerinin birbirine yakın aritmetik ortalama değerlerine sahip olduğunu ortaya koymaktadır. Belge yönetimi sistemleri ise etkinlik alanı belirlenmeye çalışılan tüm unsurlarda en düşük aritmetik ortalama değerine sahip sistemdir.

\section{Sistemlerin Genel Değerlendirmesi}

Kurumsal bilgi/belge sistemlerinin analizinde katılımcıların kullandıkları dört sisteme ilişkin genel değerlendirmeleri Tablo V'de verilmektedir. 
Tablo V. Sistemlerin Genel Değerlendirmesi (N=337)

\begin{tabular}{|c|c|c|c|c|c|c|c|c|c|c|c|c|}
\hline & \multicolumn{2}{|c|}{ Görüş Yok } & \multicolumn{2}{|c|}{ Zayıf } & \multicolumn{2}{|c|}{ Düşük } & \multicolumn{2}{|c|}{ Orta } & \multicolumn{2}{|c|}{ İyi } & \multicolumn{2}{|c|}{ Çok İyi } \\
\hline & $\mathbf{N}$ & $\%$ & $\mathbf{N}$ & $\%$ & $\mathbf{N}$ & $\%$ & $\mathbf{N}$ & $\%$ & $\mathbf{N}$ & $\%$ & $\mathbf{N}$ & $\%$ \\
\hline DYS & 12 & 3,6 & 6 & 1,8 & 19 & 5,6 & 93 & 27,6 & 160 & 47,5 & 47 & 13,9 \\
\hline wiç & 1 & 0,3 & 4 & 1,2 & 17 & 5 & 103 & 30,6 & 158 & 46,9 & 54 & 16 \\
\hline BYS & 40 & 11,9 & 4 & 1,2 & 29 & 8,6 & 114 & 33,8 & 116 & 34,4 & 34 & 10,1 \\
\hline E-posta & 4 & 1,2 & 3 & 0,9 & 15 & 4,5 & 76 & 22,6 & 155 & 46 & 84 & 24,9 \\
\hline
\end{tabular}

DYS: Doküman Yönetim Sistemleri.

BYS: Belge/Evrak Sistemleri
Wiç: Web Iç̧erik Yönetim Sistemleri.

E-posta: E-posta sistemleri olmak üzere.

Kurumsal sistemler genel olarak değerlendirildiğinde belge yönetimi sistemleri dışındaki sistemler katılımcıların en az \%60'ı tarafından iyi ve çok iyi bulunmuştur. Bulgulara göre e-posta sistemleri katılımcıların \%70,9'u tarafından iyi ve çok iyi olarak nitelendirilirken, bu sistemleri web içerik yönetimi sistemleri ve doküman yönetimi sistemleri (sırasıyla \%62,9 ve \%61,4) takip etmiştir. Ayrıca belge yönetim sistemleri ile web içerik yönetimi sistemleri katılımcılar tarafından diğer sistemlere göre daha yüksek oranlarda orta düzeyde değerlendirilmiştir (sırasıyla \%33,8 ve \%30,6). Belge yönetim sistemleri diğer sistemlere göre düşük ve zayıf olarak değerlendirmiştir. Katılımcıların doküman yönetimi, web içerik yönetimi, e-posta ve evrak/belge yönetimi sistemlerine ilişkin ortalama değerleri Şekil 6'da gösterilmektedir.

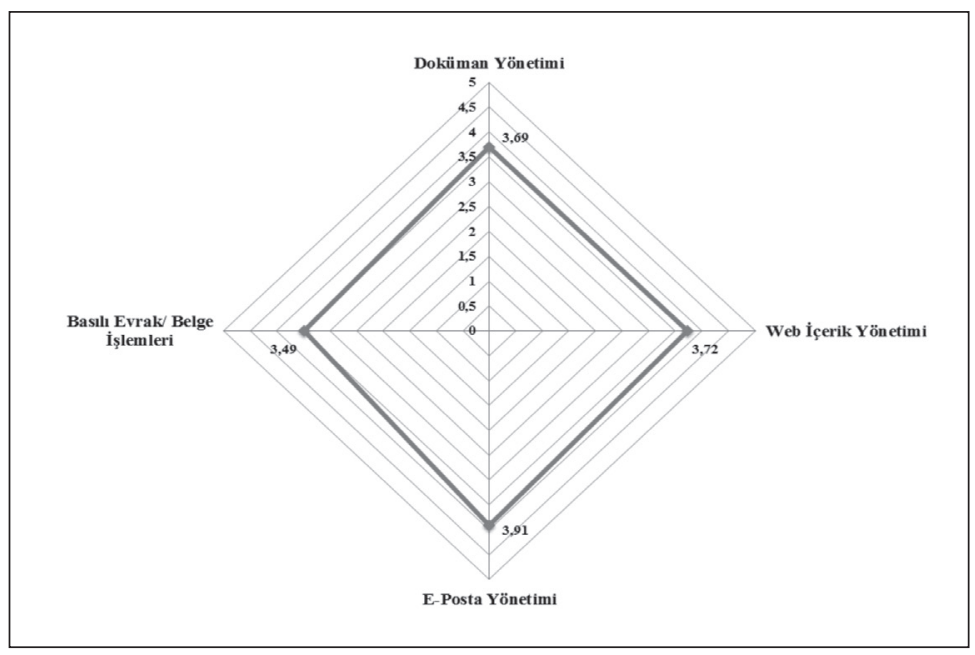

Şekil 6. Sistemlerin Genel Değerlendirmesi 
Katılımcıların kurumsal uygulamalarda kullandıkları sistemlere yönelik değerlendirmelerine ilişkin genel aritmetik ortalamalar arasında e-posta yönetimi sistemleri en yüksek değere sahiptir ( $\bar{x}=3,91 ; \sigma=0,857$ ). E-posta yönetimi sistemlerini web içerik yönetimi sistemleri ve doküman yönetimi sistemleri takip etmektedir (sırasıyla $\bar{x}=3,72 ; \sigma=0,836$ ve $\bar{x}=3,69 ; \sigma=0,857$ ). Belge yönetimi ile ilgili sistemler ise en düşük ortalamaya sahip sistemlerdir ( $\bar{x}=3,49 ; \sigma=0,870)$.

\section{Sonuç ve Öneriler}

Araştırmamız kapsamında Türkiye'de savunma sanayii alanında faaliyet gösteren bir organizasyonun içerik yönetimi uygulamalarında kullandığı doküman yönetimi, web içerik yönetimi, belge yönetimi ve e-posta yönetimi sistemleri, kurumsal bilginin yönetiminde ve kurumsal iş süreçlerinde kullanımı etkileyen unsurlar açısından değerlendirilmiş̧tir. Bu çerçevede sistemlerin, tasarım, içerik zenginliği, bilgi erişim, bilgi güvenliği, içerik yönetimine dönük politikalar ile arşivleme ve uzun süreli koruma özellikleri çalışanların bakış açılarından ele alınmıştır.

Araştırmamız sonucunda bulgulardan da görüldüğü gibi savunma sanayii organizasyonunda tasarım, içerik zenginliği, kurumsal iletişim, bilgi güvenliği, bilgi erişim ve içerik yönetimine dönük politikalar açısından etkinliği en yüksek olan sistem e-posta yönetimi yönetimidir. Doküman yönetim sistemleri ise arşivleme ve uzun süreli koruma açısından diğer sistemlere göre daha yüksek etkililik değerine sahip sistemlerdir.

Sistemleri genel olarak ele aldığımızda bilgi güvenliği ile ilgili analizlerin dışındaki tüm analizlerin orta ile iyi seviyeleri arasında olduğu ve sistemlerin genel olarak etkililik oranlarının iyiye yakın düzeylerde seyrettiği görülmektedir. Ayrıca belge yönetim sistemlerinin analiz edilen bütün unsurlarda diğer sistemlere göre düşük oranlarda bulunması da araştırmamızda elde edilen bir diğer sonuç olarak dikkati çekmektedir.

Yapılan analizlerden, kurum içi e-posta yönetimi sisteminin diğer sistemlere göre daha iyi bir düzeyde olduğu, belge yönetimi sistemlerinin ise geliştirilmesi en gerekli alan olduğu sonucu ortaya çıkmaktadır. Bu çerçevede analiz edilen içerik yönetimi uygulamalarından belge yönetimi sistemlerinde, belgelerin yaşam döngüsü göz önüne alınarak iyileştirmelerin yapılması gerekmektedir. Ayrıca kurumun bütününü kapsayan, farklı sistemler arasında veri transferine olanak tanıyan bir kurumsal içerik yönetimi sisteminin yapılandırılmasıyla bu çalışma kapsamında ele alınan sistemlerin standart bir yapıya kavuşması ve kurumsal içerik yönetimi sisteminin belirli aralıklarla kullanıcılar açısından analiz edilmesi araştırmamızın önerileri arasında yer almaktadır. 


\section{Kaynakça}

AllM. (2009). 22 Temmuz, 2009 tarihinde from http://www.aiim.org/aboutaiim/ecm-erm-bpmassociation.aspx adresinden erişildi.

AlIM. (2011). About AlIM. 25 Şubat 2011 tarihinde http://www.aiim.org/About adresinden erişildi.

AllM Europe ve AlIM International. (2007). ECM roadmap. 10 Ağustos 2009 tarihinde http://www. aiim.org.uk/publications/roadmap/poster_content.asp adresinden erişildi.

Alsup, M. (2004). ECM - The new rationale. AlIM E-Doc Magazine, March/April. 17 Kasım 2010 tarihinde http://www.gimmal.com/Publications/Documents/ECM_ The_New_Rationale.pdf adresinden erişildi.

Broadbent, R. E. (2009). A Functional framework for content management. Yayımlanmamış Yüksek Lisans Tezi, Utah: Brigham Young University.

Chieu, T.C., Zeng, L. ve Mohindra, A. (2008). An extensible enterprise content management system with service component architecture. IEEE International Conference on Service Operations and Logistics and Informatics içinde (ss. 1131-1137). Pekin: IEEE

Content Management. (2009). 12 Eylül 2009 tarihinde http://en.wikipedia.org/wiki/Content_ management adresinden erişildi.

Content Management-junction (2011). About enterprise content management, its purpose, need \& benefits. 23 Şubat 2011 tarihinde http://www.content-management-junction.com/enterprise$\mathrm{cm} . \mathrm{html}$ adresinden erişildi.

Çakmak, T. (2011). Kurumsal içerik yönetimi kapsamında bilgi ve belge sistemlerinin bir kurum örneğinde değerlendirilmesi. Yayınlanmamış yüksek lisans tezi, Hacettepe Üniversitesi, Ankara.

Dilnutt, R (2006) Surviving the information explosion. IEE Engineering Management, 16(1), 39-41.

Enterprise Content Management. (2009). Wikipedia web sitesinden 12 Ağustos 2009 tarihinde http://en.wikipedia.org/wiki/Enterprise_content_management adresinden erişildi.

Gupta, V. K., Govindarajan, S. ve Johnson, T. (2001). Overview of content management approaches and strategies. Electronic Markets 11(4), 281 - 288.

Jenkins, T., Köhler, W. ve Shackleton, J. (2005). Enterprise content management methods: what you need to know?. Kanada: Open Text Corporation.

Kampffmeyer, U. (2006). ECM-enterprise content management. Project Consult: Hamburg. 7 Kasım 2009 tarihinde http://www.projectconsult.net/Files/ECM_White\%20Paper_kff_ 2006. pdf adresinden erişildi.

McNay, H. E. (2002). Enterprise content management: an overview. Professional Communication Conference, 2002. IPCC 2002. Proceedings. IEEE International içinde (ss. 396-402). Portland: IEEE.

Mescan, S. (2004). Why content management should be part of every organisation's global strategy. The Information Management Journal, July/August, 54-57.

Nakano, R. (2002). Web content management: a collaborative approach. Boston: Addison-Wesley.

National Archives and Records Service of South Africa. (2006). Managing electronic records in governmental bodies: policy, principles and requirements. Pretoria: National Archives and Records Service of South Africa. 
O'Callaghan, R. ve Smits, M. (2005). A Strategy Development Process for Enterprise Content Management. ECIS 2005 Proceedings. 24 Mart 2010 tarihinde http://is2.lse.ac.uk/asp/ aspecis/20050110.pdf adresinden erişildi.

Oxford Dictionary. (2011). Content. 12 Mart 2011 tarihinde http://oxforddictionaries.com/view/ entry/m_en_gb0174940?rskey=sRKZ7T\&result=2\#m_en_gb0174940 adresinden erişildi.

Ozan, Ö. (2009). CMS, LMS, LCMS kavramları. Akademik Bilişim'09 - XI. Akademik Bilişim Konferansı bildirileri içinde (ss.171-176). Şanlıurfa: Harran Üniversitesi.

Paivarinta, T. ve Munkvold, B. E. (2005). Enterprise content management: an integrated perspective on information management. Proceedings of the Thirty-Eighth Hawaii International Conference on System Sciences (HICSS-38) içinde (ss.1-10). Hawaii: IEEE Computer Society Press.

Reimer, J.A. (2002). Enterprise content management. Datenbanken Spektrum, 2 (4), 17-35.

Shegda, K.M., Bell, T., Chin, K. ve Gilbert, M.R .( 2007). Magic quadrant for enterprise content management. Gartner Inc.

Smith, H. A. ve McKeen, J. D. (2003) Developments in practice: enterprise content management. Communications of AIS, 11, 647-659.

Sprehe, J. T. (2005). The positive benefits of electronic records management in the context of enterprise content management. Government Information Quarterly, 22(2), 297-303.

Stephens, D. O. ve Wallace, R.C. (2003). Electronic records retention: new strategies for data life cycle management, Lenexa: ARMA International.

Türk Dil Kurumu. (2005). Türkçe sözlük (3.bs.). Ankara: Türk Dil Kurumu.

Tyrväinen, P., Salminen, A., ve Päivärinta, T. (2003). Introduction to the enterprise content management minitrack. Proceedings of the 36th Hawaii International Conference on Systems Sciences içinde. Hawaii: IEEE Computer Society Press,

Tyrväinen, P., Päivärinta, T., Salminen, A. ve livari, J. (2006) Characterizing the evolving research on enterprise content management. European Journal of Information Systems, 15(6), 627-634.

UCDAVIS. (2009a). Web content management initiative. 18 Eylül 2009 tarihinde http://cms.ucdavis. edu/aboutcms.shtml adresinden erişildi.

Vural, Z. B. A. (2005). Kurum kültürü ve örgütsel iletişim (Gnşl. bs.). İstanbul: İletişim

Wilkoff, N., Walker, J., Root, N. ve Dalton, J. (2001) What's next for content management? Cambridge: Forrester Research Inc. 26 Şubat 2010 tarihinde http://www.forrester.com/ER/Research/ Techlnsight/Excerpt/0,4109,13920,00.html adresinden erişildi. 